\title{
Preoperative Electroencephalographic Investigation in Temporal Lobe Epilepsy: Extracranial and Intracranial Recordings
}

\author{
Pierre Gloor
}

\begin{abstract}
Preoperative EEG investigations of patients with temporal lobe seizures include extracranial interictal and ictal recordings during wakefulness and sleep, including long-term EEG and video-monitoring. Interictal epileptiform discharges when evaluated conservatively and in conjunction with other EEG and non-EEG localizing information, provide valuable guidance for the identification of the area to be resected, as do ictal recordings. When extracranial EEG features in conjunction with non-EEG data provide conflicting localizing information, intracranial recordings with stereotaxically implanted depth and epidural electrodes are used. Intracranial recordings must be designed to avoid biasing the exploration strategy in favor of one's preferred localizing hypothesis. Patients with evidence for bitemporal epileptogenic dysfunction in extracranial EEG recordings are suitable candidates for intracranial recordings. The majority of the patients explored in this manner show that all or more than $80 \%$ of their seizures arise from one temporal lobe. Excision of that lobe yields satisfactory results in a fair proportion of these patients. The number of satisfactory outcomes is, however, still somewhat less than in patients with unilateral temporal foci in extracranial EEG recordings.
\end{abstract}

RÉSUMÉ: Investigations préopératoires dans l'épilepsie temporale: enregistrements extra- et intracrâniens. Les investigations préopératoires de malades souffrant d'épilepsie temporale comprennent des enregistrements extracrâniens intercritiques et critiques durant la veille et le sommeil, incluant le "monitoring" EEG et vidéo à long terme. Les décharges épileptiques intercritiques fournissent des informations diagnostiques de valeur à condition qu'elles soient évaluées avec un sens critique approprié et interprétées eu égard à d'autres données localisatrices, électroencéphalographiques et autres. Il en est de même des enregistrements critiques. Lorsque les données de l'EEG extracrânien sont en conflit avec celles d'origine non-EEG, on procède à des enregistrements intracrâniens. Deux types d'électrodes sont alors utilisés: 10 des électrodes profondes insérées par un procédé stéréotaxique, 20 des électrodes épidurales. Les enregistrements intracrâniens doivent être conçus selon un plan qui évite d'introduire un biais favorisant une hypothèse localisatrice de prédilection. Les malades présentant dans leur EEG extracrâniens des signes de dysfonction épileptique bitemporale sont des sujets appropriés pour une exploration intracrânienne. Chez la plupart des malades soumis à une telle exploration, toutes leurs crises ou plus que $80 \%$ débutent dans un seul lobe temporal. Chez un bon nombre de ces malades les résultats thérapeutiques d'une exérèse de ce lobe sont satisfaisants. Ce nombre est cependant quelque peu inférieur à celui qu'on obtient suite à la lobectomie temporale chez les malades présentant des foyers temporaux unilatéraux à l'enregistrement EEG extracrânien.

Can. J. Neurol. Sci. 1991; 18: 554-558

It should be stated at the outset that a decision to operate on an epileptic patient should not be based on EEG evidence alone; nor should that evidence alone determine which area should be removed. Localizing EEG evidence must always be evaluated in the context of other localizing information which can be derived from the clinical seizure pattern, neurological signs (if present, although they are often missing), evidence of structural or metabolic pathology in skull X-rays (which even today, in the era of sophisticated imaging techniques, still has its value), CT scans and MRI scans, PET scans or SPECT scans, and from the neuropsychological test profile. Ideally the localizing evidence from all these sources should converge. If it does not, the nature and the weight of the incongruous evidence must be pondered carefully before a decision to operate is made. ${ }^{1}$

\section{Extracranial Electroencephalographic Exploration}

The EEG provides three types of localizing evidence: (i) interictal epileptiform abnormalities; (ii) interictal non-epileptiform abnormalities; and, (iii) ictal epileptiform abnormalities. ${ }^{2-4}$

\section{Interictal Electroencephalographic Evidence}

The major source of localizing evidence in the interictal EEG is the presence of recurrent interictal epileptiform discharges in the form of spikes, sharp waves and spike-and-wave complexes.

From the Montreal Neurological Institute, Montreal

Reprint requests to: Pierre Gloor M.D., Montreal Neurological Institute, 3801 University Street, Montreal, Quebec, Canada H3A 2B4 
This evidence is usually easy to obtain in patients suffering from medically intractable seizures. It is also commonly considered to be easy to recognize. However, one should be conservative in interpreting interictal spike or sharp-wave discharges. Not every wave with a sharp wave form is epileptiform. The criteria by which epileptiform sharp waves can be distinguished from nonepileptiform ones have been delineated in earlier publications. ${ }^{3,5}$

Non-epileptiform abnormalities carry less diagnostic weight than the epileptiform ones, but should not be overlooked. They include depression or irregularity of background activity, or localized continuous or intermittent slow waves on the side of the epileptogenic lesion.

The strategy of collecting interictal data is straightforward. One normally starts with a waking scalp recording in the hope of finding interictal discharges, for if present in a waking record, this provides the most reliable localizing interictal evidence (see below). The electrodes of the 10-20 international electrode placement system do not, however, adequately explore the basal and mesial surface of the temporal lobe, the area most prominently implicated in temporal lobe seizures. ${ }^{4}$

After an initial scalp recording, one would therefore proceed to investigate a patient with one or the other variety of basal electrodes. The most useful ones are sphenoidal electrodes aimed at the foramen ovale. 4,6-8 Thin wire electrodes introduced with a rigid guide wire that is removed once they are inserted, are the most useful, since they can be left in place for several days without risk to the patient. They thus make repeated and chronic recordings including ictal recordings possible.

Zygomatic electrodes, placed on the zygomatic arch or minisphenoidal electrodes, ${ }^{9}$ fine needles inserted below this arch, may provide recordings from the basal temporal surface which in some cases are almost as good as those obtained with sphenoidal electrodes and are therefore methods that one may want to use in ambulatory practice or in children.

The next step in the extracranial EEG work-up is to record during sleep. ${ }^{4}$ Even in cases in which the waking record has provided interictal epileptiform abnormality, it is still useful to obtain a sleep recording, since it greatly increases the yield of interictal epileptiform abnormalities. This does not come without a price, however. A recent study undertaken in our laboratory ${ }^{10}$ showed localization during slow-wave sleep to be less crisp than in wakefulness; thus a patient exhibiting only unilateral interictal epileptiform discharges when awake may begin to show contralateral discharges during sleep, raising the question of a bitemporal epileptiform problem. Usually in these cases there is, however, no shift of the predominance of epileptiform discharges to the other side during sleep. In REM sleep, the number of epileptiform discharges regresses again and their spatial extent shrinks and becomes restricted to the major epileptogenic area, as has been reported for depth electrode recordings by Montplaisir et al. 1 Localizing evidence obtained during REM sleep thus appears to be the most reliable. However, the restriction of epileptiform discharges during REM sleep may lead to its total disappearance, which weakens the usefulness of recordings during that sleep stage.

Since interictal epileptiform abnormality are often bilateral, particularly during sleep, it is useful to quantify the number of epileptiform discharges to establish the degree of lateralizing predominance. This can be done automatically with an appropri- ate computer program that prints out the numbers appearing in various regions. 12,13

It is also important to evaluate the consistency of the localization prior to surgical treatment. Multiple examinations are therefore mandatory. If localizations vary from one examination to another, this considerably lessens the usefulness of the diagnostic information obtained.

Withdrawal from anticonvulsant medication (which must be done slowly) often helps in increasing the diagnostic yield of interictal abnormalities in the EEG. We know now, however, that this usually occurs only if drug withdrawal has led to seizures. ${ }^{14}$

How useful are interictal discharges as a guide for making a decision to operate on a patient? The ideal finding is that in which all interictal discharges originate from one temporal region during both wakefulness and sleep, preferably associated with some abnormality of background activity in the same area. Relatively few cases completely satisfy this optimal criterion. Commonly there is some measure of bilaterality of interictal abnormality, particularly in sleep. If, however, a lateralized temporal focus consistently stands out as the major focal area of epileptiform firing, this information is quite compelling, although it must be evaluated in the context of all the other localizing information derived from EEG and non-EEG sources. ${ }^{1}$ Difficulties arise when the number of bilateral independent interictal discharges is large, especially if this is the case also during wakefulness and a strong lateralizing predominance cannot be established. In such a case the additional localizing evidence must be evaluated carefully. The most useful ones are ictal onset localized to the site of the predominant interictal abnormality and the demonstration of a clear-cut lesion in one temporal lobe in imaging studies, particularly if associated with congruent lateralized neurological signs, both supporting the lateralizing and localizing diagnosis derived from the EEG. If such additional information is not forthcoming, exploration with stereotaxically implanted depth electrodes possibly in combination with epidural or subdural electrodes is indicated. 3.4

There has been a tendency in the last few decades to downplay the importance of the localizing evidence provided by interictal epileptiform discharge derived from extracranial recordings. There is no doubt that if such evidence is interpreted in a non-rigorous fashion and if the criteria of selection of cases is not sufficiently strict, errors in localizing diagnosis will be made. It should, however, be stressed that in most of the hundreds of patients operated by Penfield for the relief of temporal lobe seizures, the EEG evidence he had available was interictal and was mostly derived from waking EEG recordings. ${ }^{2}$ His results of surgical treatment were as good as those of more recent series in which more sophisticated techniques have been employed. ${ }^{15-17}$ This should not, however, be misinterpreted to mean that one should limit oneself only to the collection of interictal EEG data, since undoubtedly many patients who are now appropriate surgical candidates would have been denied surgical treatment in these early years when the EEG evidence used for decision making was in most cases interictal. Penfield's record, however, does indicate that the interictal EEG abnormality is a useful diagnostic guide which should not be underevaluated. 


\section{Ictal Electroencephalographic Abnormalities}

To obtain ictal recordings in patients with seizures is more difficult than to collect interictal data, even with the help of long-term monitoring. Furthermore, even if seizures are recorded, the EEG data obtained from scalp and sphenoidal recordings are often difficult to interpret. 3,4,18 Muscle and movement artefact may obscure such recordings from the very beginning, and even if the artefact problem is absent or minimal, the EEG onset not infrequently may appear generalized, especially if it consists of a sudden flattening of the background activity, or the ictal pattern may be ill-defined morphologically. There may be some lateralizing or localizing predominance which, however, may not be sufficiently clear-cut to inspire confidence in its reliability. Furthermore, video monitoring may reveal that the first clinical signs appear before any change is apparent in the EEG. In all these instances a definitive localizing diagnosis as to ictal onset cannot be made.

The ideal ictal recording is one in which there is a clearly localized onset of rhythmic or fast low-voltage activity in one temporal region or in one of its subdivisions such as the mesial temporal area as recorded with sphenoidal electrodes. This EEG onset should precede or at least be concomitant with that of the first clinical signs. Ideally this area should coincide with that of the maximum interictal spiking and with the localizing evidence provided by non-EEG data. ${ }^{18}$ Misleading localizing evidence may sometimes be provided by ictal recordings in patients who have a gross localized lesion in one of the temporal lobes. ${ }^{19}$ In such instances ictal discharge may appear to arise predominantly from the temporal lobe opposite to that harboring the lesion. The more destructive the lesion and the larger its size, the more likely is the occurrence of such a misleading lateralization and localization. Difficulty arises with small lesions in cases in which there is a discrepancy in the lateralization of apparent seizure onset in the EEG and the localization of such a lesion. In most of these instances, depth electrode recordings are mandatory.

It is difficult to make any definitive statements about the usefulness of the extracranial ictal EEG onset as a guide for surgical treatment. ${ }^{4}$ Intuitively one would feel that a demonstrated local onset of seizure discharge should be the most reliable localization sign for the purpose of guiding surgical treatment. Unfortunately, for the reasons enumerated above, this is not always the case. A systematic evaluation of the true contribution of localizing value of ictal onsets in extracranial recordings is difficult to perform, because surgical decisions are never based solely on ictal EEG evidence and, whenever there is a serious conflict between the localization of ictal versus non-ictal EEG abnormality, the patient is subjected to intracranial recordings. For the interictal epileptiform abnormality the situation is somewhat different, because in earlier years many patients had been operated upon with few ictal EEG recordings having been available for evaluation (see above).

\section{LONG-TERM MONITORING}

The advent of adequate technology to make long-term monitoring feasible has revolutionized the diagnostic work-up of epileptic patients. ${ }^{20}$ Especially when combined with video recordings, this method provides means to correlate interictal, ictal and clinical features obtained during both wakefulness and sleep. This review is not the place to discuss the various techno- logical approaches to long-term monitoring which obviously may vary from one center to another. To make such methods practically useful, however, some data reduction is desirable. Continuous computer-assisted supervision of the records and online analysis of interictal data are in our experience some of the most useful tools in long-term monitoring. 20,21

\section{INTRACRANIAL RECORDINGS}

When extracranial EEG recordings have failed to provide good localizing evidence, it becomes necessary to proceed with intracranial recordings. 1,22 Before embarking on an intracranial study, one must have data from extracranial EEG, clinical, imaging and neuropsychological sources that are sufficient to allow one to formulate a number of working hypotheses concerning the possible localization of the patient's epileptogenic focus. ${ }^{23,24}$ Intracranial recordings must be designed in a way that they make it possible to determine which of the alternative hypotheses is correct. Obviously electrodes should be implanted in areas in which the patient's seizures are suspected to originate. One must, however, be mindful of the very narrow range of vision provided by intracranial electrodes 23,24 and one must therefore avoid devising an intracranial strategy of exploration that merely serves to confirm one's diagnostic prejudices. Thus one should explore temporal lobes bilaterally even if one is fairly convinced that the seizures originate from one side only, for if one implants electrodes only on the side "of suspicion" seizure activity will only be recorded on that side, even if this may result from spread of discharge from the other side. For the same reason implantation into one lobe only is not advisable, even if one is convinced that the patient's seizures are temporal in origin. Obviously there is a limit to how many areas one can explore, but if the patient's pre-implantation data are carefully analyzed, it is usually not too difficult to devise a rational strategy that is sufficiently objective to avoid the pitfalls of self-fulfilling prophecies.

The choice of methods of intracranial recordings is a point on which there exists a wide spectrum of opinions. ${ }^{25,26}$ In our institution we emphasize stereotaxic exploration, particularly for the temporal lobes, because this is the only reliable method for adequately exploring the mesial temporal structures such as the amygdala, hippocampus and parahippocampal gyrus with simultaneous recordings of superficial and deep sulcal isocortex. ${ }^{27-29}$ Originally we had limited ourselves to stereotaxic recordings, but later began to use, in addition, subdural strips and, more recently, epidural electrodes insulated except for their tips touching the dura which provide just as reliable recordings as subdural electrodes. With the help of stereotaxic angiograms and MRI scans it is possible to place these electrodes in precisely identifiable areas of the brain. 28,29

Armed with these techniques, the yield of electrographic information provided by intracranial recordings is often overwhelming. Even 16-channel recording techniques often appear limited. The ideal strategy is to have a multielectrode recording system providing 32 channels or more and to record all the data with a referential technique reformatting the information later on in whatever combination of montages one would want to see the data displayed. We are just beginning to use such a technique, but have as yet not had sufficient experience with it to evaluate its results. 
In patients with bitemporal epileptiform abnormalities one finds an abundance of interictal abnormality in depth recordings and this abnormality is present in both lobes, which considering the selection of these patients is not surprising. It is often difficult to establish whether the interictal epileptiform abnormalities predominate in one lobe or the other and we have therefore not used interictal evidence as a guide for surgery.

The decision to operate was therefore based on the identification of the area(s) from which seizures originate. Some of these have a strictly focal, others a regional onset. In a recent review of 57 bitemporal cases explored with depth electrodes, ${ }^{30}$ we found that the largest group of patients $(25-44 \%)$ consisted of those in whom all seizures originated exclusively from one temporal lobe; in the next largest group ( 19 patients $=33 \%$ ) $80 \%$ or more seizures arose from one lobe with the remainder originating contralaterally. The number of patients with a lesser or no lateralized predominance of onset was much smaller $(8=14 \%)$. Relatively few patients $(5-9 \%)$ had more diffuse onsets in the temporal and the frontal lobes on one side or bilaterally.

To determine which of these patterns are reliable guides predicting the likelihood of a favorable outcome from resective surgery of one temporal lobe, we have up to now been generous in offering surgical treatment to all patients in whom the data taken together provided some justification to operate on one side, even though predominance of seizure onset in one temporal lobe may have been rather weak.

The therapeutic results from operating on these patients were as follows: ${ }^{31}$ when all or more than $80 \%$ of the seizures arose from one temporal lobe 18 out of the 48 patients operated (47\%) derived a significant benefit from surgery with 14 having remained seizure free. The much smaller group of patients in whom the predominance of onset to one side was less than $80 \%$ or who in addition to temporal also had extratemporal seizure onsets did rather poorly. None, except one, of these cases had a satisfactory outcome from surgery, even when the lobe with the predominant seizure onset had been removed. However, $6 / 10$ of these patients still had more than a $50 \%$ reduction in seizure incidence. It is thus possible to treat surgically medically refractory patients in whom the evidence $a$ priori suggests that both temporal lobes are epileptogenic.

It is noteworthy that even in the group of our patients with bitemporal extracranial epileptiform abnormalities in whom all seizures where shown in depth electrode recordings to originate from one temporal lobe, the incidence of good results was still less than in those patients with unilateral temporal foci as defined by extracranial EEG recordings alone in whom temporal lobectomy had been performed. ${ }^{15-17,32,33}$ This again indirectly demonstrates that a careful extracranial approach to EEG analysis in patients considered to be surgical candidates is worthwhile and in many cases sufficient to reach a surgical decision and that intracranial recordings with depth electrodes or other techniques need not be applied in all patients considered for temporal lobectomy.

\section{REFERENCES}

1. Gloor P. Commentary: Approaches to localization of the epileptogenic lesion. In: Engel J, ed. Surgical Treatment of the Epilepsies. New York: Raven Press, 1987; 97-100.

2. Penfield W, Jasper HH. Epilepsy and the Functional Anatomy of the Human Brain. Boston: Little, Brown \& Co., 1954.
3. Gloor P. Contributions of electroencephalography and electrocorticography to the neurosurgical treatment of the epilepsies. In: Purpura DP, Penry JK, Walter RD, eds. Advances in Neurology, Vol. 8: Neurosurgical Management of the Epilepsies. New York: Raven Press, 1975; 59-105.

4. Quesney LF. Extracranial EEG evaluation. In: Engel J, ed. Surgical Treatment of the Epilepsies. New York: Raven Press, 1987; 129 166.

5. Gloor P. The EEG and differential diagnosis of epilepsy. In: van Duijn H, Donker DNJ, van Huffelen AC, eds. Current Concepts in Clinical Neurophysiology: Didactic Lectures of the 9th International Congress of Electroencephalography and Clinical Neurophysiology. The Hague: NV Drukkerij Trio, 1977; 19-21.

6. Rovit R, Gloor P, Rasmussen T. Sphenoidal electrodes in the electroencephalographic study of patients with temporal lobe epilepsy: An evaluation. J Neurosurg 1961; 18: 151-158.

7. Ives JR, Gloor P. New sphenoidal electrode assembly to permit long-term monitoring of the patient's ictal or interictal EEG. Electroenceph Clin Neurophysiol 1977; 42: 575-580.

8. Ives JR, Gloor P. Update: Chronic sphenoidal electrodes. Electroenceph Clin Neurophysiol 1978; 44: 789-790.

9. Laxer KD. Mini-sphenoidal electrodes in the investigation of seizures. Electroenceph Clin Neurophysiol 1984; 58: 127-129.

10. Sammaritano M, Gigli GL, Gotman J. Interictal spiking during wakefulness and sleep and the localization of epileptic foci in temporal lobe epilepsy. Neurol 1991; 41: 290-297.

11. Montplaisir J, Laverdière M, Saint-Hilaire JM, et al. Sleep and focal epilepsy: A study of patients implanted with depth electrodes. In: Wolf P, Dam M, Dreifuss FE, eds. Advances in Epileptology. New York: Raven Press, 1987; 705-707.

12. Gotman J, Gloor P. Automatic recognition and quantification of interictal epileptic activity in the human scalp EEG. Electroenceph Clin Neurophysiol 1976; 41: 513-529.

13. Gotman J. Automatic recognition of interictal spikes. In: Gotman J, Ives JR, Gloor P, eds. Long-term Monitoring in Epilepsy. Electroenceph Clin Neurophysiol (Suppl 37). Amsterdam: Elsevier Science Publishers BV, 1985; 93-114.

14. Gotman J, Marciani MG. Electroencephalographic spiking activity, drug levels, and seizure occurrence in epileptic patients. Ann Neurol 1985; 17: 597-603.

15. Penfield W, Flanigin H. Surgical therapy of temporal lobe seizures. Arch Neurol Psychiatry 1950; 64: 491-500.

16. Bloom D, Jasper HH, Rasmussen T. Surgical therapy in patients with temporal lobe seizures and bilateral EEG abnormality. Epilepsia 1960; 1: 351-365.

17. Jasper HH, Arfel-Capdeville G, Rasmussen T. Evaluation of EEG and cortical electrographic studies for prognosis of seizures following surgical excision of epileptogenic lesions. Epilepsia 1961; 2: 130-137.

18. Quesney LF, Gloor P. Localization of epileptic foci. In: Gotman J, Ives JR, Gloor P, eds. Long-Term Monitoring in Epilepsy (EEG Suppl 37). Amsterdam: Elsevier Science Publishers BV, 1985; 165-200.

19. Sammaritano M, de Lotbinière A, Andermann, et al. False lateralization by surface EEG of seizure onset in patients with temporal lobe epilepsy and gross focal cerebral lesions. Ann Neurol 1987; 21: 361-369.

20. Gotman J, Ives JR, Gloor P, eds. Long-Term Monitoring in Epilepsy. Electroenceph Clin Neurophysiol (Suppl 37). Amsterdam: Elsevier Science Publishers BV, 1985; 444

21. Gotman J, Ives JR, Gloor P, et al. Monitoring at the Montreal Neurological Institute. In: Gotman J, Ives JR, Gloor P, eds. Long-term Monitoring in Epilepsy (EEG Suppl 37). Amsterdam: Elsevier Science Publishers BV, 1985; 327-340.

22. Gloor P. Postscript: When are noninvasive tests enough? In: Engel J, ed. Surgical Treatment of the Epilepsies. New York: Raven Press, 1987; 259-261.

23. Gloor P. Electroencephalography and the role of intracerebral depth electrode recordings in the selection of patients for surgical treatment of epilepsy. In: Porter RJ, Mattson R, Ward AA, et al., eds. Advances in Epileptology: XVth Epilepsy International Symposium. New York: Raven Press, 1984; 433-437. 
24. Gloor P. Volume conductor principles: Their application to the surface and depth electroencephalogram. In: Wieser HG, Elger CE, eds. Presurgical Evaluation of Epileptics. Berlin, Heidelberg: Springer-Verlag, 1987; 59-68.

25. Engel J, ed. Surgical Treatment of the Epilepsies. New York: Raven Press, 1987.

26. Wieser HG, Elger CE, eds. Presurgical Evaluation of Epileptics. Basics, Techniques, Implications. Berlin, New York, London: Springer Verlag, 1987.

27. Gloor P, Olivier A, Quesney, et al. The role of the limbic system in experiential phenomena of temporal lobe epilepsy. Ann Neurol 1982; 12: 129-143.

28. Olivier A, de Lotbinière A. Stereotaxic techniques in epilepsy. In: Tasker RR, ed. Neurosurgery State of the Art Reviews, Vol. 2. Philadelphia: Hanley \& Belfus, Inc. 1987.

29. Olivier A, Marchand E, Peters T, et al. Depth electrode implantation at the Montreal Neurological Institute and Hospital. In: Engel J, ed. Surgical Treatment of the Epilepsies. New York: Raven Press, 1987; 595-601.
30. So N, Gloor P, Quesney LF, et al. Depth electrode investigations in patients with bitemporal epileptiform abnormalities. Ann Neurol 1989; 25: 423-431.

31. So N, Olivier A, Andermann, et al. Results of surgical treatment in patients with bitemporal epileptiform abnormalities. Ann Neurol 1989; 25: 432-439.

32. Rasmussen T. Surgical treatment of complex partial seizures: results, lessons and problems. Epilepsia 1983; 24 (Suppl 1): 565576.

33. Olivier A. Surgical management of complex partial seizures. In: Nistico G, Di Pierri R, Meinardi H, eds. Epilepsy: An Update on Research and Therapy. New York: Liss, 1903; 309-324. 